\title{
Distinction of Entailment and Presupposition
}

\author{
Xiaohui Xu \\ School of Foreign Languages, Qingdao University of Science and Technology \\ Qingdao 266061, China \\ E-mail: xxhqust@tom.com
}

The paper is part of the results of the social science fund project "Study on college teachers' role based on the environment of internet plus class teaching" of Qingdao University of Science and Technology in 2008.

\begin{abstract}
In this passage, the definitions of entailment and presupposition are pointed out, and distinctions of them are shown through examples.
\end{abstract}

Keywords: Entailment, Presupposition

\section{Introduction}

In talking about sentence relations and truth in semantics, there are several sentence relations: $\mathrm{a} \& \mathrm{~b}$ are synonymous, $\mathrm{a}$ entails $b$, a contradicts $b$, a presupposes $b$, a is a tautology, a is a contradiction. In all the relations, entailment and presupposition are often to be confused. So we can use several examples to show the difference between them.

\section{Definition and Distinction}

\subsection{Definition}

First, some semanticists have claimed that the meaning relations discussed in example 1 can be given a more rigorous definition. The claim is that there are fixed truth relations between sentences which hold regardless of the empirical truth of the sentences. We can examine the claim by looking at the semantic relation of entailment.

Example 1: a. The anarchist assassinated the emperor.

b. The emperor died.

Presupposition has been an important topic in semantics: the 1970s in particular saw lively debates in the literature. Books devoted largely to the subject include Kempson (1975), D. Wilson (1975), etc, and important papers include J. D. Fodor(1979) and Wilson and Sperber (1979).

To presuppose something means to assume it, and the narrower technical use in semantics is related to this.

In example 2, a sentence is said to presuppose b sentence.

Example 2: a. I don't regret leaving London.

b. I left London.

\subsection{Distinction}

\subsubsection{Theory of Distinction}

How to distinguish the two relations? The relation of the two sentences can be tested in the following tables:

1. Composite truth table for entailment 2.Composite truth table for presupposition

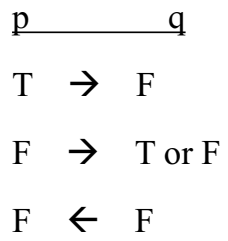

p

$F \leftarrow F$

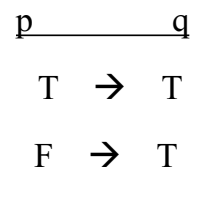

$\mathrm{T}$ or $\mathrm{F} \leftarrow \mathrm{T}$ 


\section{$\mathrm{T}$ or $\mathrm{F} \leftarrow \mathrm{T}$}

\section{$?(\mathrm{~T} \vee \mathrm{F}) \leftarrow \mathrm{F}$}

We can see how this would work for our examples:

Step 1: If $\mathrm{p}$ is true, then $\mathrm{q}$ is automatically true? Yes.

Step 2: If $\mathrm{q}$ is false, is $\mathrm{p}$ also false? Yes.

Step 3: Then $\mathrm{p}$ entails q. Note if $\mathrm{p}$ is false then we can't say anything about $\mathrm{q}$; it can be either true or false. And if $\mathrm{q}$ is true we can't say anything about $\mathrm{p}$; it can be either true or false.

The relation is shown in figure 1.

Step 1: If $\mathrm{p}$ is true then $\mathrm{q}$ is true.

Step 2: If $\mathrm{p}$ is false, then $\mathrm{q}$ is still true.

Step 3: If $\mathrm{q}$ is true, $\mathrm{p}$ could be either true or false.

Step 4: If $\mathrm{q}$ is false, the status of $\mathrm{p}$ is dubious, possibly neither true nor false.

The relation is shown in figure 2 .

\subsubsection{Examples}

There are many other examples in exercises in 4.4, page 103 of the book Semantics written by John I. Saeed, 2000. According to the method we have discussed above, No. 1, 3, 5 are presuppositions, No. 2 and 4 are entailments. Let's take 1 and 2 for example.

1. a. Dave is angry because Jim crashed the car.

b. Jim crashed the car.

From the table of presupposition, we can get that if 'Dave is angry because Jim crashed the car' is true, then 'Jim crashed the car' is true.

If Dave isn't angry because Jim crashed the car, then 'Jim crashed the car' is still true.

If Jim 'crashed the car' is true, Dave may be angry or not.

If Jim 'crashed the car' is false, that means maybe nothing happened about the car, so sentence a is meaningless.

2. a. Zaire is bigger than Alaska.

b. Alaska is smaller than Zaire.

From the table of entailment, we can get that if 'Zaire is bigger than Alaska' is true, then 'Alaska is smaller than Zaire' is true.

If 'Alaska is smaller than Zaire' is false, then 'Zaire is bigger than Alaska' is false.

If 'Zaire is bigger than Alaska' is false, then 'Alaska is smaller than Zaire' may be true or false; if 'Alaska is smaller than Zaire' is true, then 'Zaire is bigger than Alaska' is true or false.

Other Ways of Distinction

We can also make a judgment in lexical relationship or in syntactic of whether it is an entailment.

Let's take exercise 2 for example:

It can also be analyzed in syntactic. The two versions of the sentence will entail one another. Sentence a entail sentence b, and vice versa. That means, 'Zaire is bigger than Alaska' entail 'Alaska is smaller than Zaire' and vice versa.

In some other examples, it can also be decided in lexical. Let's look at example 1 again. 'The anarchist assassinated the emperor', that means the person killed the emperor in some way and the emperor is dead now. So in lexical, assassinate somebody entail that somebody died. In this way, we can also draw that the relation is entailment.

These are the other two ways of drawing the conclusion, which are easier than the three or four steps of judgment.

\section{Conclusion}

In studying sentence relations and truth, learning how to distinguish entailment and presupposition is very useful in understanding the meaning of sentences semantically and pragmatically.

\section{References}

JohnI. Saeed. (2000). Semantics. Foreign Language Teaching and Research Press.

Kempson, Ruth M. (1975). Presupposition and the Delimitation of Semantics. Cambridge University Press.

Wilson, D. (1975). Presupposition and Non-truth Conditional Semantics. New York: Academic Press. 